\title{
THE EFFECTS OF FOUR SELECTED COMPONENTS OF OPPORTUNITY TO LEARN ON MATHEMATICS ACHIEVEMENT OF GRADE 12 STUDENTS
}

By Janet Maria Collie-Patterson

https://doi.org/10.15362/ijbs.v12i0.53

\section{Abstract}

The effects of four selected components of the opportunity to learn mathematics achievement of grade twelve students in New Providence, Bahamas. The purpose of this study was to determine if a single dimension of opportunity to learn (OTL) could be identified using four selected components of teachers, students, schools, and classroom characteristics; and to determine if each of the four components of OTL was related to mathematics achievement as measured by the results of the June 1999, Bahamas General Certificate of Secondary Education mathematics examination.

The findings of this study indicated that the model-data-fit was reasonable, suggesting that a significant relationship existed between opportunity to learn and three selected components of teachers, students, and school characteristics. The fourth component, classroom characteristics, was not significantly related to OTL. Each of the four components of schools, students, teachers, and classroom characteristics were significantly related to mathematics achievement.

\section{Introduction}

The concept of Opportunity to Learn (OTL) originated more than thirty-five years ago in the work of John Carroll (1963). In his model of school learning, Carroll defined OTL as the "time allowed for learning" (p. 727). Using time as the sole parameter for defining opportunity, he invited researchers to find ways of measuring opportunity to learn in terms of "the actual time available to individual students to learn in view of the pacing of instruction" (p. 732). Over the years, the vast amount of research related to the correlation between 
achievement and school processes has provided policy makers with the impetus to become interested in OTL as a measure of classroom learning and the implementation of the curriculum in different schools. Consequently, the need arose for the expansion of the types of indicators previously used in collecting and reporting data relating to OTL indicators (McDonnell, 1995).

OTL now includes not only the content of the curriculum but also how the materials are presented to students. Stevens (1996) indicated that the OTL framework must encompass factors such as content coverage, content exposure, and content emphasis. Further, Stevens insisted that the quality of instructional delivery greatly influences a teacher's instructional practices and student learning. Smithson, Porter, and Blank (1995) categorized indicators of OTL as: inputs, processes, and outputs. Researchers in the Third International Mathematics and Science Survey(TIMSS) suggested that "educational opportunity" and "a new rhetoric about opportunity" (p. 345) should replace the traditional OTL (Schmidt \& McKnight, 1995). A model of educational opportunity was developed to collect data on students' educational opportunity for the TIMSS project. The model consisted of four constructs: curriculum, classroom, school, and student variables and sought the answers to four questions: "What are students expected to learn? .... Who delivers the instruction? .... How is the instruction organized? ... . What have students learned? ..." (pp. 348-350). These four questions formed the basis of this research.

\section{The Statement of the Problem}

The National Education Goals Report (1997) showed that in the United States in 1996, $21 \%$ of Grade 4 students, $24 \%$ of Grade 8 students and $16 \%$ of Grade 12 students had met the Goals Panel's performance standard in mathematics. The report indicated that U. S. students' achievement in mathematics continued to fall below the performance standard set by the Goals Panel. While mathematics achievement of students in the U. S. is below standard, other countries appear to follow the same trend.

The geographical area of The Bahamas, for example, is experiencing a similar trend with regard to mathematics achievement. Many Bahamian students' scores fell below the acceptable standards in mathematics achievement as indicated by the Bahamas Junior Certificate (BJC) and the Bahamas General Certificate of Secondary Education (BGCSE) examinations. These examinations are prepared by the Testing and Evaluation Center and are administered at the end of the ninth and twelfth grade, respectively. The Testing and Evaluation report on mathematics BJC and BGCSE examinations results for the school year 1997-1998, given at the opening of the Department of Education teachers' in-service workshop (August 17, 1998) indicated that the national averages for both BJC and BGCSE mathematics continued to fall below an acceptable level of achievement. The results of the mathematics BJC and BGCSE examinations alluded to serious problems in the area of mathematics and expressed reasons for grave concern and further investigation.

The purpose of this study was to examine the relationship between mathematics achievement, opportunity to learn, and the four components of teacher characteristics, student characteristics, school characteristics, and classroom characteristics. This study sought answers to the following research questions:

1. What is the relationship between Opportunity to Learn (OTL) and the four selected components of teacher characteristics, student characteristics, 
school characteristics, and classroom characteristics?

2. Is there a relationship between each of the four selected components of OTL and mathematics achievement?

\section{Hypotheses}

$\mathrm{H1}$ :There is a relationship between OTL and the four selected components of teacher characteristics, student characteristics, school characteristics, and classroom characteristics.

$\mathrm{H} 2$ :There is a significant relationship between mathematics achievement and each of the four selected components of OTL.

\section{Participants of the Study}

The primary sample for this study consisted of 1015 Grade 12 students from six public schools and six private schools in New Providence, Bahamas. Questionnaires were administered to 1036 students during the Spring semester 1999. Although questionnaires were returned from 1036 students, 21 of them did not give their names and as a result the researcher was unable to obtain their Bahamas Junior Certificate (BJC) and Bahamas General Certificate of Secondary Examination results. These 21 students were excluded from the study. Additionally, 552 students did not respond to all items on the questionnaires. However, the number of missing responses per item was relatively small. The secondary sample for this study consisted of 52 mathematics teachers who taught these students in the 10th, 11th, or 12th grade. Of the 60 teachers who returned the questionnaires, 52 of them were matched with the student sample and were, therefore, included in the study.

\section{Instrumentation}

A set of questionnaires, some parts developed by the researcher, others selected from published instruments, was used to collect the data and determine scores for each of the four selected components: teacher characteristics, student characteristics, school characteristics, and classroom characteristics, that constituted OTL. The set of questionnaires contains a Student Questionnaire and a Teacher Questionnaire.

The student questionnaire was divided into two parts and consisted of 38 items. Part I contained 18 items (developed by the researcher) and were used to provide data on the selected components of student characteristics and classroom characteristics. Part II of this questionnaire was a reprint of the School Climate Inventory Form-S of the Instructional Leadership Evaluation Assessment and Development Inventory (ILEAD) instrument that was printed with the permission of MetriTech Inc., the copyright holder, to collect data on school characteristics (1986).

The teacher questionnaire was developed by the researcher and consisted of 15 items. This questionnaire supplied demographic data as well as data for teacher characteristics and classroom characteristics.

\section{The Measures of Mathematics Achievement}

The mathematics achievement data consisted of archival data on individual students' grades from the Bahamas Junior Certificate mathematics examination which was administered to Grade 9 students in 1996 and grades from the General Certificate of Secondary Education mathematics examination that 
was administered to Grade 12 students in June 1999. The grades for student participants were obtained from the 1996 results of the BJC examination and the 1999 results of the BGCSE examination at The Testing and Evaluation Section of the Department of Education, New Providence, Bahamas. These were used as each student's prior ability and mathematics achievement variables, respectively.

\section{Analysis of Data}

The data were analyzed using structural equation modeling, confirmatory factor analysis, multiple linear regression, AMOS Version 4.0, and SPSS Version 9.0. All hypotheses were tested for significance at the .05 level. Confirmatory Factor analysis was used to test the data against a recursive second order a priori hypothetical structural equation model and to determine the best model-data-fit. The results from this analysis were used to test hypothesis 1 . Multiple linear regression was used to test hypothesis 2.

\section{Results}

Hypothesis 1 was tested using confirmatory factor analysis using the program AMOS Version 4.0 (Arbuckle \& Wothke 1999) and SPSS Version 9.0.

\section{Hypothesis 1}

There is a relationship between opportunity to learn (OTL) and the four selected components of teacher characteristics, student characteristics, school characteristics, and classroom characteristics.

To test hypothesis 1, structural equation modeling (Bentler, 1995) was used. The theoretically recursive $a$ priori second order model was submitted to a confirmatory factor analysis using Amos Version 4.0 and SPSS Version 9.0 and maximum likelihood estimation. The original model depicted in Figure 2 (see Appendix) was analyzed using confirmatory factor analysis.

The goodness-of-fit statistic $\left(\chi^{2}(94, \underline{\mathrm{N}}=463)=269.789, \underline{\mathrm{p}}=.006\right)$, with relative

$$
\left(\chi^{2} / \mathrm{df}=2.870, \mathrm{RMSEA}=.064, \mathrm{AIC}=353.789 \text { was accepted } .\right.
$$

All other correlations are significant at $\mathrm{p}<.05$.

- means no correlation.

According to the relevant literature ( Bentler, 1995; Kline, 1998) the modeldata-fit was reasonable. The results indicated that three of the four components of teacher characteristics, student characteristics, school characteristics, and classroom characteristics contributed to the model, but the contribution of the set of classroom characteristics was not significant (see Table 1).

\section{Table 1}


Standardized Maximum Likelihood Estimates for Parameters of the Revised Model for the OTL Data Set

\begin{tabular}{|c|c|c|c|c|}
\hline \multirow[b]{2}{*}{ Cause } & \multicolumn{4}{|c|}{ Effect Variable } \\
\hline & Teacher & Student & School & Classroom \\
\hline Oft & .18 & .64 & .81 & oوs \\
\hline Strength of climate & - & - & .35 & - \\
\hline Educational background & .44 & - & - & .30 \\
\hline Professional development & .73 & - & - & - \\
\hline Years of teaching experience & -.38 & - & - & - \\
\hline Student prior ability & - & $-.11^{\mathrm{ns}}$ & - & .42 \\
\hline Socioeconomic status & - & $-.03^{n s}$ & - & - \\
\hline Attitude toward school & - & .67 & - & - \\
\hline Commitment & - & - & .73 & - \\
\hline Affiliation & -.14 & - & .75 & - \\
\hline Power & - & - & .41 & $.10^{\mathrm{ns}}$ \\
\hline Accomplishment & -.24 & .75 & & \\
\hline Recognition & - & - & .63 & - \\
\hline Instructional strategies & - & - & - & .94 \\
\hline Manipulative use & .14 & - & - & .39 \\
\hline Course & - & - & - & .16 \\
\hline
\end{tabular}

To test hypothesis 2, multiple regression was used to analyze each of the hypothesized four groups of predictor variables (indicators). The predictor variables for each component were tested to predict a significant relationship between criterion variable of Bahamas General Certificate of Secondary Education (1999) mathematics results (the indicator of mathematics achievement) and each of four groups (components of OTL).

\section{Hypothesis 2}

There is a significant relationship between mathematics achievement and each of the four selected components of opportunity to learn.

Table 2a Results of Predicting the Bahamas General Certificate of Secondary Education Mathematics Scores from the Classroom Component of Opportunity to Learn

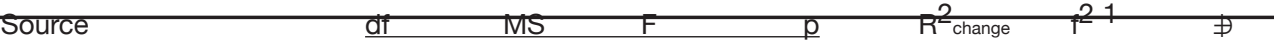

$472.16 \quad 153.55$

$.001 a$

.738

.37

$.545 a$

Note: a. Tested against the full model.

b. Predictors in the full model: (Constant), Teaching strategy, Course taking, Use of manipulatives.

There was a significant relationship between mathematics achievement and 
the set of classroom characteristics of course taking, manipulative use, and teaching strategies (see Table 2a). However, when taken individually, use of manipulatives was not significantly related to mathematics achievement.

Table $2 \boldsymbol{b}$ Results of Predicting the Bahamas General Certificate of Secondary Education Mathematics Scores from the Teacher Component of Opportunity to Learn

\begin{tabular}{|c|c|c|c|c|c|c|c|}
\hline Source & df & MS & $\mathrm{F}$ & م & $\mathrm{B}^{2}$ change & $\mathrm{f}^{21}$ & $\oplus$ \\
\hline Professtonal development & 1 & 165.43 & 42.39 & $.001 a$ & .043 & .047 & -.244 \\
\hline Educational background & 1 & 136.38 & 34.94 & $.001 a$ & .053 & .057 & .219 \\
\hline Years of teaching experience & 1 & .25 & .06 & $.800 \mathrm{a}$ & & & -.009 \\
\hline Teacher & 3 & 81.76 & 20.95 & $.001 b$ & .078 & .085 & \\
\hline Residual & 741 & 3.90 & & & & & \\
\hline
\end{tabular}

Note a. Tested against the full model.

b. Predictors in the full model: (Constant), Years of teaching experience, Professional development, and Educational background.

There was a significant relationship between mathematics achievement and the set of teacher characteristics that included educational background, years of teaching experience, and professional development (see Table $2 \mathrm{~b}$ ). When taken individually, however, years of teaching experience was not significantly related to mathematics achievement, and professional development was negatively related to mathematics achievement.

Table 2c Results of Predicting the Bahamas General Certificate of Secondary Education Mathematics Scores from the School Component of Opportunity to Learn

\begin{tabular}{|c|c|c|c|c|c|c|c|}
\hline Soufer & $d f$ & MS & $\mathrm{F}$ & & $R^{2}$ chran & $f 21$ & $\not$ \\
\hline Affliation & $T$ & 142.99 & 39.30 & $.001 a$ & .054 & .061 & .308 \\
\hline Power & 1 & 22.61 & 6.21 & $.013 a$ & .009 & .010 & .100 \\
\hline Strength of Climate & 1 & 38.78 & 10.66 & $.001 a$ & .015 & .017 & -.129 \\
\hline Recognition & 1 & 59.19 & 16.27 & $.001 a$ & .022 & .025 & -.183 \\
\hline Commitment & 1 & 25.03 & 6.88 & $.009 a$ & .009 & .010 & .129 \\
\hline Accomplishment & 1 & 98.52 & 27.08 & $.001 a$ & .037 & .042 & -.244 \\
\hline School & 7 & 52.47 & 14.42 & $.001 b$ & .119 & .135 & \\
\hline Residual & 640 & 3.64 & & & & & \\
\hline
\end{tabular}

Note: a. Tested against the full model.

b. Predictors in the full model: (Constant), Affiliation, Power, Strength of Climate, Recognition, Commitment, and Accomplishment.

There was a significant relationship between mathematics achievement and the set of school characteristics of commitment, affiliation, recognition, power, strength of climate, and accomplishment (see Table 2c). However, when taken individually, strength of climate, recognition, and accomplishment were negatively related to mathematics achievement. 
Secondary Education Mathematics Scores from the Student Component of Opportunity to Learn

\begin{tabular}{|c|c|c|c|c|c|c|c|}
\hline Source & df & MS & $F$ & م & $\mathrm{B}^{2}$ change & $f^{21}$ & $\oplus$ \\
\hline Soeiveonomiestatus & 1 & 13.78 & 8.76 & $.003 a$ & .007 & .017 & .084 \\
\hline Parental involvement & 1 & 3.60 & 2.29 & $.131 a$ & .002 & & .043 \\
\hline Attitude toward school & 1 & 32.20 & 20.46 & $.001 a$ & .016 & .04 & -.129 \\
\hline Student s prior ability & 1 & 983.37 & 625.37 & $.001 a$ & .480 & 1.197 & .718 \\
\hline Student & 4 & 306.87 & 195.04 & $.001 b$ & .599 & 1.494 & \\
\hline Residual & 552 & 1.57 & & & & & \\
\hline Note: a. Tested agains & ell mor & & & & & & \\
\hline
\end{tabular}

There was a significant relationship between mathematics achievement and the set of student characteristics of student's prior ability, socioeconomic status, attitude toward school, and parental involvement (see Table 2d). However, when taken individually, parental involvement was not significantly related to mathematics achievement, and attitude toward school was negatively related to mathematics achievement.

In order of effect size, the component of classroom characteristics was most important, followed by school characteristics, then student characteristics, and, lastly, teacher characteristics.

\section{Discussion}

Based on the model developed by TIMSS researchers (Schmidt \& McKnight, 1995), this study investigated the relationship between opportunity to learn (OTL) and the four components of teacher characteristics, school characteristics, student characteristics, and classroom characteristics on the Bahamian school population. The findings of this study support the results that there was also a significant relationship between OTL and the three selected components of student characteristics, school characteristics, and teacher characteristics. Confirmation of the model for OTL firmly establishes the four components of teacher characteristics, school characteristics, student characteristics, and classroom characteristics as defining OTL. Further research is needed to sharpen the operational definitions of these four components. In particular, classroom characteristics need further study since its relationship to OTL was not significant. There could be several reasons for this lack of significance. First, a direct measure of content of lesson taught, a very important indicator of the classroom characteristics, was beyond the scope of this study. Second, manipulative use and teaching strategies were self-reported by teachers. Some teachers did not have access to manipulatives such as graphing calculators, algebra tiles, and computers in their classrooms, or if they were available, they were reportedly not used by many of the teachers.

The review of relevant literature on teacher characteristics indicated that mathematics teachers play a prominent role in increasing mathematics achievement. The findings of this research indicated that the set of teacher components that included professional development, teaching experience, and educational background was significantly related to mathematics achievement. Kinney (1997-1998) found that a successful professional development 
program appeared to foster positive student achievement. Waller (1932) found that a crucial element in motivating students to learn was the emotional bond they formed with their teachers. The results of recent research studies indicated that students enjoy greater satisfaction and experience higher achievement in classrooms that have personal student-teacher relationship, innovative teaching methods and clearly defined sets of rules (Moos, 1979). In response to the statements "teachers and students trust one another", and "teachers and students treat each other with respect" the students disagreed with both of these statements. The findings of this study indicated that teachers played a small but significantly negative role in their students' mathematics achievement. This finding implies that there was a reported lack of trust between teachers and students, a serious issue that should be addressed by the Bahamian education institutions.

There are two areas of concern with the set of components of teacher characteristics in relation to achievement. First, the indicator years of teaching experience was not significantly related to mathematics achievement. A possible reason for this might be found in the changes in mathematics instruction that experienced teachers may not be aware of and, as a result, could not implement. Duke (1993) suggested that professional growth is a rare commodity among more experienced teachers. On the other hand, Irwin (1994) argued that when a person enters the teaching arena he or she is involved in a lifelong learning process that began before he or she entered a college of education and continues throughout his or her career. This study confirms that Irwin's view of lifelong learning for teachers is still an ideal, not yet reality.

Second, the findings of this study showed a significant negative relationship between professional development and mathematics achievement. Restating, students of teachers who reported attending more mathematics workshops and conferences did not do as well in the Bahamas General Certificate of Secondary Education (BGCSE) mathematics examination as those who reported attending fewer workshops and conferences. Several possibilities could account for these findings. First, the transfer to classroom practice of information obtained from workshops and conferences may be minimal. Also, there may be a lack of follow-up after workshops or conferences to ensure theory to practice transfer. Teachers probably need collaborative environments that foster continuous learning and enhance their effectiveness in the classrooms (Morton, 1993). The workshops or conferences attended by mathematics teachers may not have been relevant to what they are required to teach. Often teachers are not consulted to determine what their needs are. For example, the major need might not be in content knowledge, but in pedagogy. This finding is supported by the results from The Rand Change Agent Study (McLaughlin, 1991): a teacher with new information about classroom processes does not necessarily apply this information in the classroom. One conclusion to be drawn from this study is that Bahamian mathematics teachers should participate in identifying future professional development programs that affect them. At the very least, additional staff development should do no harm.

Although all indicators of the set of school components were significantly related to mathematics achievement, the findings of this study showed that school had a small to medium effect on mathematics achievement. Rogus (1983) found that two of the central components of successful schools are high 
expectations of, and communication with members of the school community. Johnson and Johnson (1979) suggested that the school's environment is largely the sum of the classroom environment within the school. Also, the perception by students and parents of what is happening in school is dependent on what is happening in the classrooms and how they perceive that students and teachers are interacting. The findings of this study indicated that three out of six of the indicators of school climate were negatively related to mathematics achievement. Strength of climate, recognition, and accomplishment were significantly negative, indicating that the students who were low on the climate scale were high on mathematics achievement and those who were high on the climate scale were low on mathematics achievement. This finding is not supported by the literature. Therefore, Bahamian schools should undertake a systematic program to improve school climate. This affects all aspects of the school, not just mathematics.

Although the set of classroom components was not significantly related to OTL, they were significantly related to, and made a large contribution to mathematics achievement. This finding is supported by the result of a study conducted by Goodlad (1982) and his associates who found that the level of achievement is dependent on what goes on in the classroom. The finding relating to OTL was probed earlier in the discussion. The relation of the set of classroom components to mathematics achievement deserves further discussion. The findings of this research also indicated that students in Bahamian classrooms were divided into at least three different curricular tracks: the track with students who did not write the BGCSE mathematics examination, the track with students who wrote the core level mathematics examination, and the track with students who wrote the extended level mathematics examination. Oakes and Lipton (1994) advised that tracking amplifies earlier differences that existed among students. For example, students with similar backgrounds show marked differences in their achievement when tracked in earlier grades. As students enter the secondary schools, having had no opportunity to catch up, the differences become even more pronounced. The findings of this study suggest that there were pronounced differences in mathematics achievement (as measured by the BGCSE mathematics examination) among Bahamian students and these differences relate to the classroom components, particularly the component of course taking.

With the large number of students in the lower tracks in most of the schools, the use of manipulatives in the mathematics classroom could be used to help students develop and understand mathematical concepts, procedures, and other aspects of mathematics (Szendrei, 1996; Kober, 1991; Clements \& McMillen, 1996); promote active learning, create motivation, and alleviate boredom (Kober, 1991); and improve students' understanding of mathematics (Kennedy, 1986). Many research studies have shown that the use of manipulatives has a positive effect on students' achievement in mathematics (Kober, 1991). However, taken individually, in this study, the use of manipulatives was not significantly related to mathematics achievement. Bahamian mathematics classes reportedly made minimal use of manipulatives. Therefore, a low relationship between manipulative and mathematics achievement is not surprising.

Students are the most important players in the learning process, whether as passive observers or willing participants. It was no surprise that the set of stu- 
dent components of student's prior ability, attitude toward school, socioeconomic status and parental involvement made the largest contribution to mathematics achievement. Taken individually, the effect size indicated that student's prior ability made the largest contribution to mathematics achievement. Student's prior ability is determined by a combination of factors relating to home background and schooling history (Leder, 1992). Boyer (1993) proposed that students must have a solid foundation in the relevant school disciplines in order to achieve in those areas. Wolf (1977) found that socioeconomic status was directly related to achievement. Oakes (1985) argued that students' attitudes greatly affect the learning opportunities provided for them by their teachers. The findings of this study indicated that taken individually, parental involvement was the only member of the set that was not significantly related to mathematics achievement. In addition, taken individually, attitude toward school was found to be negatively related to mathematics achievement.

The finding of this study that parental involvement was not a significant factor in students' mathematics achievement was not supported by the literature. Some researchers have shown that parents play the most critical role in the educational achievement of their children (Boyer, 1993; Ballantine, 1989). Koerner (1999) found that parental involvement had a major impact on students' achievement. Koerner found that $87 \%$ of the students who earned As or Bs reported that parental involvement and aid were crucial in their achievement; while $50 \%$ of those who received Cs or worse indicated that parents were not interested. Stevens (1996) indicated that the family supports achievement by restricting television watching time; promoting reading at home, insisting that students spend time doing homework; helping students with homework (if they can); and allowing them to spend extra time pursuing academic interests. Research studies have shown that parental involvement in the home has greater impact on children's learning than parental involvement at school (Lueder, 1998). Hence, one possible reason why parental involvement was found not to be significant in this study could be that the indicators used to measure parental involvement were largely school based. Additional parental involvement measures might increase its influence on students' mathematics achievement.

As a mathematics teacher in the Bahamian school system for many years, the researcher is aware of the many frustrations students face in mathematics classes. Over the years, many of these students have continually experienced failure in their mathematics classes. Therefore, it was not surprising that findings of this study indicated that attitude toward school was negatively related to mathematics achievement. Oakes (1985) suggested that students who experience success may develop positive attitudes toward school while students who experience failure may develop negative attitudes toward school.

The findings of this study indicated that according to effect size, the set of students' characteristics made the largest contribution $(60 \%)$ to mathematics achievement. The order in which the other components contribute to mathematics achievement from highest to lowest was, classroom characteristics (36\%), school characteristics (12\%), teacher characteristics (8\%). This was an interesting finding. In the Bahamas, mathematics teachers are usually held accountable for students' lack of mathematics achievement. Although the schools and classrooms are sometimes considered as possible causes, the students are never considered as a possible cause of their lack of mathematics 


\section{Conclusions}

Based on the data presented in this study, the following conclusions can be made:

1. A dimension of opportunity to learn can be identified from the three selected components of teacher characteristics, school characteristics, and student characteristics.

2. Mathematics achievement was significantly related to each of the four selected components of teacher characteristics, school characteristics, student characteristics, and classroom characteristics.

3. Opportunity to learn was related to mathematics achievement.

4. Student characteristics made the largest contribution to mathematics achievement when compared with school characteristics, teacher characteristics, and classroom characteristics.

\section{References}

Arbuckle, J. L., \& Wothke, W. (1999). Amos 4.0 user's guide. Chicago, IL: SmallWaters Corporation.

Ballantine, J. H. (1989). The sociology of education: A systematic analysis. (2nd ed.). New Jersey: Prentice Hall.

Bentler, P. M. (1995). ESQ structural equation program manual. Encino, CA: Multi variate Software.

Boyer, E. L. (1993). Ready to learn: A mandate for the nation. New Jersey: The Carnegie Foundation for the Advancement of Teaching.

Carroll, J. B. (1963). A model of school learning. Teachers College Record, 64 (1), 723-733.

Clements, D. \& McMillen, S. (1996). Rethinking concrete manipulatives. Teaching Children Mathematics, 2, 270-280.

Duke, D. L. (1993). Removing barriers to professional growth. Phi Delta Kappan, 74(9), 702-704 \& 710-712.

Goodlad, J. I. (1982). A study of schooling. Paper presented to the Stanford Teacher Education Project, Stanford Ca, January.

Irwin, K. (1994). Ongoing development as a teacher of mathematics. In J. Neyland (Ed.), Mathematics Education: A handbook for teachers, Vol 1, 367-374. New Zealand: Wellington College of Education.

Johnson, D. W., \& Johnson, R. T. (1979). Cooperation, competition, and individualization. In W. J. Walberg (Ed.), Educational environment and efforts: Evaluation, policy, and productivity. Berkeley, CA: McCutchan Publishing.

Kennedy, L. M. (1986). A rationale. Arithmetic Teacher, 33(6), 6-7, 32.

Kinney, C. J. (1997-1998). Building an excellent teacher corps: How Japan does it. American Educator, 21(4), 16-23.

Kline, R. B. (1998). Principles and practices of structural equation modeling. New York: Guilford Press.

Kober, N. (1991). What we know now about mathematics teaching and learning. EDTALK. (ERIC Document Reproduction Service No ED343 793).

Koerner, B. I. (1999), January 18). Parental power. US News \& World Report.

Leder, G. C. (1992). Mathematics and gender: changing perspectives. In D. A. Grouws (Ed.), Handbook of research on mathematics teaching and learning: A project of the National Council of Teachers of Mathematics. New York: Macmillan.

Lueder, D. C. (1998). Creating partnerships with parents: An educator's guide. Lancaster, PA: Technomic 
McDonnell, L. M. (1995). Opportunity to learn as a research concept and policy instrument. Educational Evaluation and Policy Analysis, 17 (3), 305322.

McLaughlin, M. W. (1991). Enabling professional development: What have we learned? In A. Lieberman \& L. Miller (Eds.), Staff development for education in the '90s: New demands, new realities, new perspectives. (2nd ed.). New York: Teachers College Press Columbia University.

Moos, R. H. (1979). Educational climates. In H. J. Walberg (Ed.), Educational environments and effects: Evaluation, policy and productivity. Berkeley, CA: McCutchan Publishing.

Morton, I. (1993). Teacher collaboration in Urban secondary schools. Eric/Cue Digest ED363 676. New York: Eric Clearinghouse on Urban Education.

National Educational Goals Panel, (1997). The National Education Goals report: Building a nation of learners. Washington, D. C.: U. S. Government Printing Office.

Oakes, J. (1985). Keeping track: How schools structures inequality. New Haven: Yale University Press.

Oakes, J. \& Lipton, M. (1994). Tracking and ability grouping: a structured barrier to access and achievement. In J. I. Goodlad \& P. Keating (Eds.), Access to knowledge: the continuing agenda for our nation's schools. Revised Edition 187-206. New York: College Entrance Examination Board.

Rogus, J. F. (1983). How principals can strengthen school performance. NASSP: Bulletin, 67 (459), 1-7.

Schmidt, W. H., \& McKnight, C. C. (1995). Surveying Educational opportunity in mathematics and science: An international perspective. Educational Evaluation and Policy Analysis, 17 (3), 337-353.

Smithson, J. L., Porter, A. C., Blank, R. K. (1995). Describing the enacted curriculum: Development and dissemination of opportunity to learn indicators in science education. Council of Chief State School Officers: Washington D.C. ( ERIC Document Reproduction Service No. ED 385 430).

Stevens, F. I. (1996). The need to expand the opportunity to learn conceptual framework: should students, parents, and school resources be included? A paper presented at the annual meeting of the American Educational Research Association (ERIC Document Reproduction Services No ED397 523).

Szendrei, J. (1996). Concrete materials in the classroom. In A. J. Bishop, K. Clements, C. Keitel, J. Kilpatrick, \& C. Laborde (Eds.), International handbook of mathematics education, part 1. Boston: Kluwer Academic Publishers.

Waller, W. (1932). Sociology of teaching. New York: Russell \& Russell.

Wolf, A. (1977). Poverty and achievement. 19, (3): National Institute of Education.

\section{Appendix}


Figure 1. Proposed relationship between OTL and the four selected components of teacher characteristics, student characteristics, schools characteristics, and

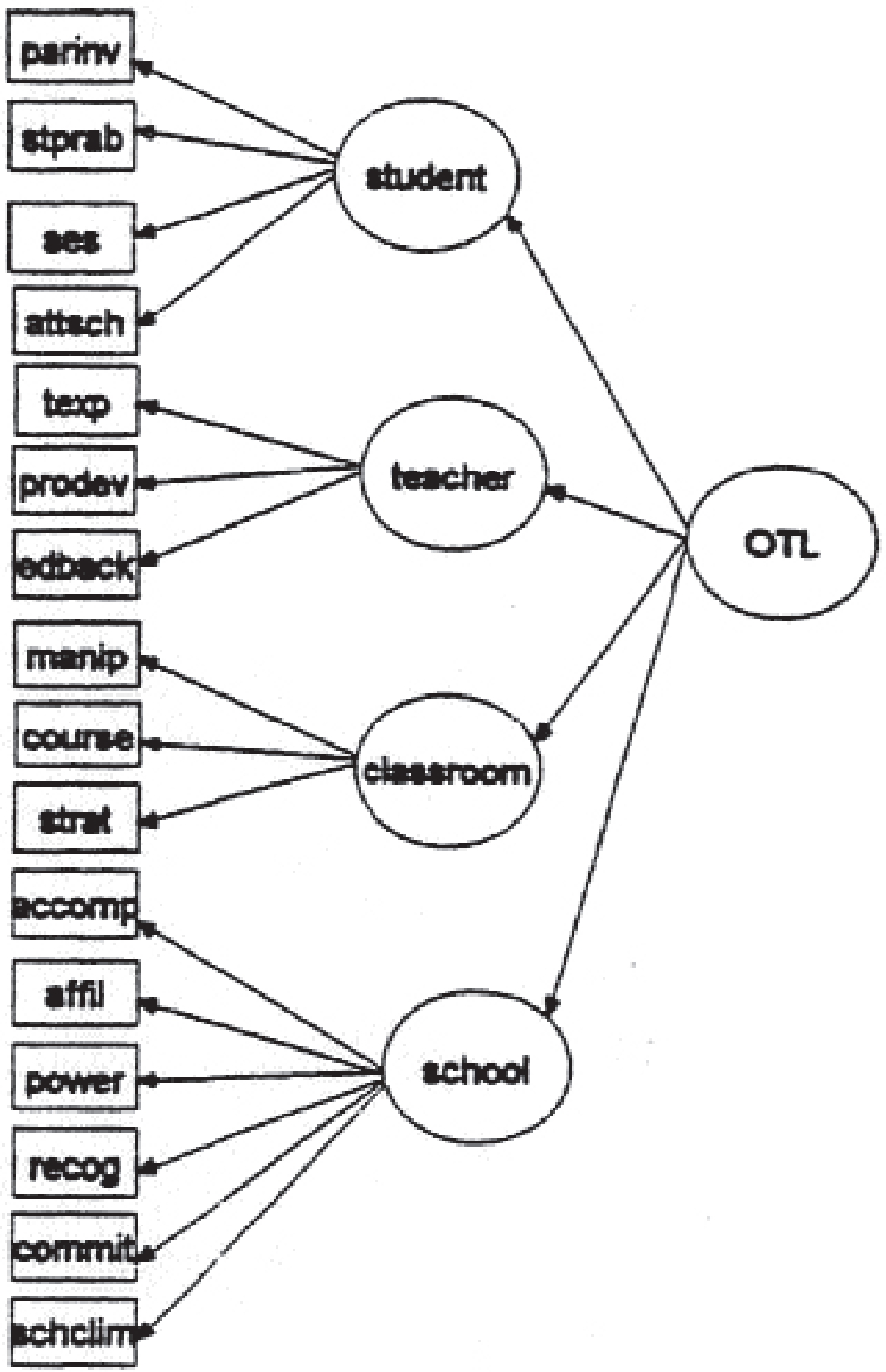

classrooms characteristics. The indicator variables are as follows: educational background (edback), teaching experience (texp), professional development (prodev), students' prior ability (stprab), socioeconomic status (ses), parental involvement (parinv), attitude toward school (attsch), commitment (commit), strength of climate (stoclim), accomplishment (accomp) recognition (recog), power, affiliation (affil), course taking (course), use of manipulatives (manip), and teaching strategies (strat).

Figure 2. The second order original structural equation model: Relationship between (OTL) opportunity to learn and the components of teacher, student, 


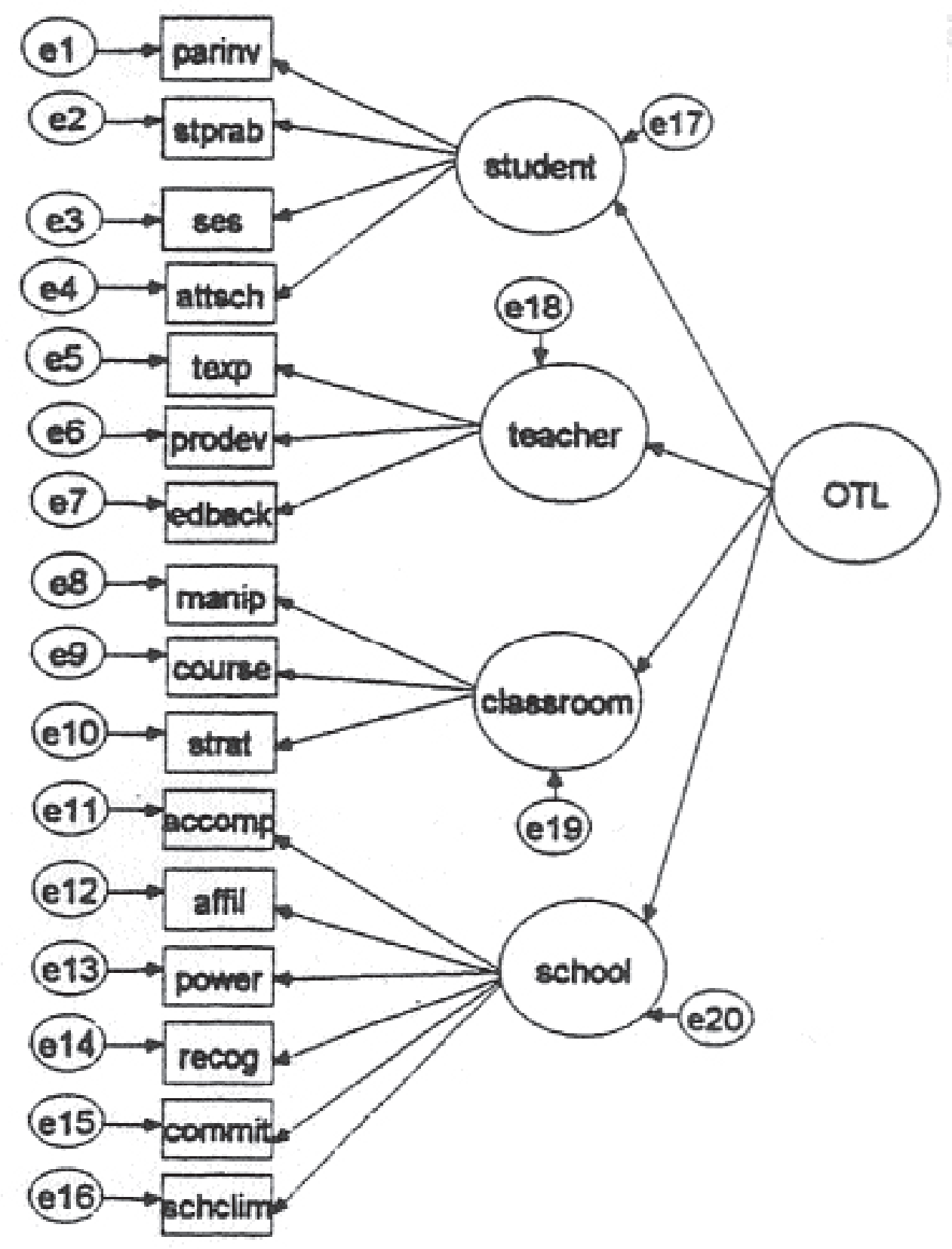

school, and classroom as measured by the indicator variables of educational background (edback), teaching experience (texp) professional development (prodev), student prior ability (stprab), socioeconomic status (ses), parental involvement (parinv) attitude toward school (attsch), commitment (commit), strength of climate (schclim), accomplishment (accomp), recognition (recog), power, affiliation (affil), use of manipulative (manip), teaching strategies (strat), and course taking (course).

Figure 3. A revised second order original structural equation model with eight new paths added: Relationship between (OTL) opportunity to learn and the components of teacher, student, school, and classroom as measured by the indi- 


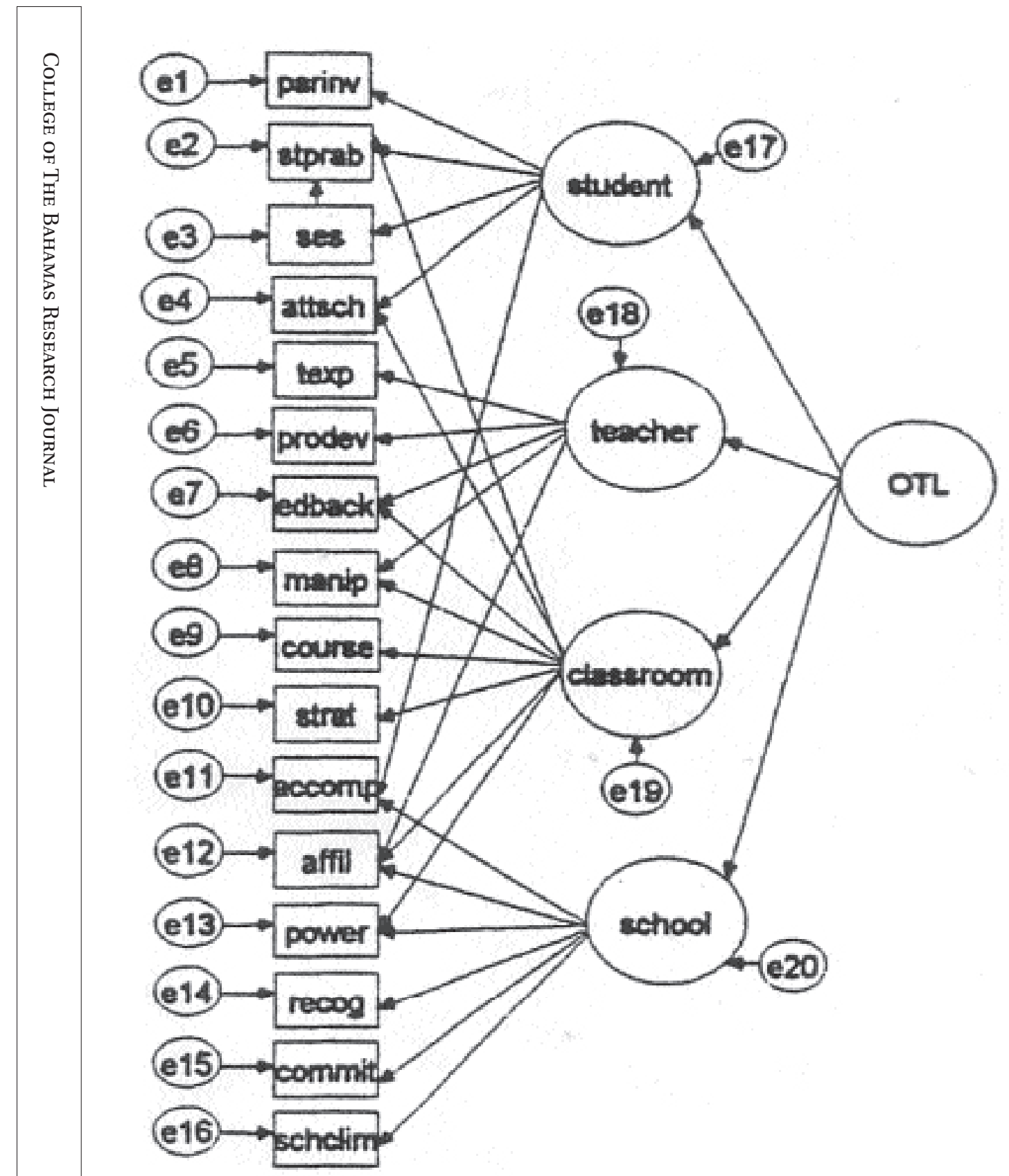

cator variables of educational background (edback), teaching experience (texp) professional development (prodev), student prior ability (stprab), socioeconomic status (ses), parental involvement (parinv), attitude toward school (attsch), commitment (commit), strength of climate (schclim), accomplishment (accomp), recognition (recog), power, affiliation (affil), use of manipulative (manip), teaching strategies (strat), and course taking (course). 
Dr. Janet Patterson is a mathematics lecturer in the Department of Mathematics, School of Natural Sciences and Environmental Studies at The College of The Bahamas. She has a Ph.D. in Secondary Education, with an emphasis in mathematics from The University of Southern Mississippi, Hattiesburg; an M.A. in mathematics form State University of New York at Buffalo; a B.A. (Second Class Honors) from the University of the West Indies. 